\title{
A EDUCAÇÃO NO ATUAL CENÁRIO POLÍTICO ECONÔMICO MUNDIAL: A DISPUTA ELEITORAL E OS RETROCESSOS NA EDUCAÇÃO
}

\begin{abstract}
s eleiçóes de 2018 se aproximam exigindo nossa atenção em relação aos $A$ programas dos candidatos e seus compromissos com a educaçáo públi11 ca, como têm observado frequentemente representantes de entidades científicas e sindicais da área de Educação, os quais ainda têm tratado da defesa dos direitos e das conquistas sociais pelos quais lutamos durante décadas e abordado também a necessidade premente de reverter os retrocessos em curso provocados pela destruição do Estado Democrático de Direito no país.
\end{abstract}

Luta que se apresenta cada vez mais complexa nesse tenso cenário de disputa eleitoral, tanto para o Executivo quanto para o Legislativo, permeado por atos de violência e de arbitrariedade jurídica, os quais introduzem insegurança e desalento à maioria da população brasileira (já abalada pelas políticas reacionárias e antipopulares do governo Temer.) Soma-se a isso a presença da grande mídia e suas manipulaçóes planejadas com o propósito não de esclarecer, mas de aumentar a incerteza popular sobre as questóes políticas em pauta e, principalmente, sobre os graves problemas sociais.

Nesse quadro de disputa eleitoral confinada ao pragmatismo de grupos de interesses que "usurparam as ideologias partidárias" (MARTINS, 2018), cresce o desânimo com a representação política. A gravidade do momento atual é inquestionável!

Com o aprofundamento da crise global do capitalismo nos últimos dez anos e a recente inserção do Brasil na divisão internacional do trabalho, as novas estratégias de acumulação de capital têm por objetivo recompor as taxas de lucro ao patamar pré-crise dos principais agentes da economia mundial. Perante a crise econômica, o governo e as empresas buscam restaurar a acumulaçáo capitalista por meio da mercantilização dos direitos sociais, como educação, saúde, previdência, desmonte da proteção trabalhista, entre outros, processo denominado apropriadamente de "acumulaçâo por espoliação" (HARVEY, 2005) ou "políticas austericidas" (BRAGA, 2017).

Em resumo, a reforma trabalhista e a liberação da terceirização indiscriminada significam o desmonte de direitos dos trabalhadores, o que levou a inclusão do país na lista suja da Organização Internacional do Trabalho (OIT), como uma das 24 naçóes que violam gravemente normas e convençôes internacionais do trabalho.

A partir de agora, deverão ser intensificadas as demissóes de trabalhadores diretos das empresas e sua substituiçẫo por trabalhadores terceirizados, que

DOI: 10.1590/ES0101-73302018v38n144ED 
serão contratados por empresas especializadas em serviços de terceirizaçáo de mão de obra. Dessa forma, é possível projetar, por exemplo, grandes contingentes de professores terceirizados nas escolas de ensino fundamental, médio e superior, bem como em creches infantis. E isso não apenas no setor privado. A legislação aprovada no Congresso, sancionada por Temer e sustentada pelo Superior Tribunal Federal (STF), abre larga brecha para a terceirização também nos serviços públicos.

Temos hoje 2,8 milhóes de crianças e adolescentes fora da escola, número que se elevará rapidamente com a espoliação dos trabalhadores promovida pelas medidas de austeridade fiscal impostas pelo governo Temer (só o Bolsa Família terá redução de $50 \%$, totalizando apenas 15 bilhóes de reais na proposta de orçamento encaminhada pelo governo federal para o próximo ano). Os retrocessos em curso impedem o Brasil de garantir a todos o direito à educaçáo pública de qualidade.

O país possui uma legislação capaz de produzir avanços educacionais significativos. Para reparar a sua histórica trajetória de atraso educacional, seria imprescindível cumprir as resoluçóes das Conferências Nacionais de Educação (Conaes) (2010 e 2014), em parte expressas nos dispositivos do Plano Nacional de Educação (PNE) (2014-2024). As Conaes mobilizaram milhôes de educadores(as) de todos os níveis, etapas e modalidades e de todos os estados da federação, contudo as metas do PNE decorrentes desse processo de mobilização democrática não têm sido prioridade da gestáo pública e não dispóem do orçamento necessário. Desde a aprovaçáo da lei, em 2014, apenas um dos dispositivos foi cumprido integralmente (aquele que determina a publicaçáo de balanços de implementaçáo), com avanços em apenas $30 \%$ nos demais e cumprimento previsto para os anos entre 2015 e 2018, conforme balanço realizado pela Campanha Nacional pelo Direito à Educação e Laboratório de Dados Educacionais da Universidade Federal do Paraná (UFPR).

Entre os atrasos está a instituição do Sistema Nacional de Educação, previsto para 2016, pré-requisito fundamental à articulação entre os sistemas de ensino, em regime de colaboração, bem como a implementação das diretrizes e metas do PNE. Na mesma situação estão as estratégias que compóem a meta 20 de financiamento e tratam da implementaçáo progressiva de conquistas sociais relevantes, o Custo Aluno Qualidade Inicial (CAQi) e o Custo Aluno Qualidade, instrumentos que preveem um padrão mínimo de financiamento da educação, de modo que se garanta qualidade em sua oferta, além do estabelecimento de um regime de colaboraçáo em que a União se responsabiliza a complementar financeiramente estados, Distrito Federal e municípios que não alcançarem o valor mínimo do financiamento planejado. O plano prevê também, via CAQi, a implementaçâo do piso do magistério e a garantia de equiparação salarial com as demais profissóes, além de investimentos na formação docente, na infraestrutura das escolas e na relação professor-aluno.

Para concretizar essa política, seria necessário aplicar $10 \%$ do produto interno bruto (PIB) em educação, conforme prevê o PNE. No entanto, o governo congelou por 20 anos (até 2036), com a aprovação da Emenda Constitucional 95, 
os investimentos da Uniáo federal nas diferentes áreas de políticas públicas, inclusive a educacional, inviabilizando essa e outras urgentes providências previstas no PNE. Esse percentual situava-se em 5,5\% do PIB em 2015, segundo o INEP, mesmo depois que o investimento público total em educação avançou do patamar de R \$ 149,2 bilhóes, em 2004, para 343,8 bilhóes em $2014{ }^{1}$.

Por outro lado, instituiçóes do Sistema S, como o Serviço Nacional de Aprendizagem Industrial (Senai), o Serviço Nacional de Aprendizagem Comercial (Senac), o Serviço Social da Indústria (Sesi) e o Serviço Social do Comércio (Sesc), para citar alguns dos exemplos mais conhecidos, recebem algo entre $\mathrm{R} \$ 16$ bilhóes e R $\$ 17$ bilhóes anuais, originados de descontos nas folhas de pagamento das empresas industriais e comerciais (FOLHA DE S.PAULO, 2018), recursos maiores do que a complementação da União ao Fundo de Manutenção e Desenvolvimento da Educação Básica e de Valorização dos Profissionais da Educação (Fundeb), cuja previsão para 2018 é de $\mathrm{R} \$ 14$ bilhóes. As contribuiçóes que sustentam esse sistema, de recolhimento compulsório, equivalem a imposto parafiscal repassado no custo das mercadorias, determinado por decreto do presidente Getúlio Vargas em 1942. Portanto, a despeito da gestão privada, constituem recursos públicos, patrimônio de toda a sociedade, cujo controle público é essencial para a democratização do acesso à educação profissional pública.

Afinal, as políticas educacionais aprovadas pelo atual governo, como a Reforma do Ensino Médio e a Base Nacional Comum Curricular (BNCC), divergem também das concepções e orientaçóes do PNE. Apesar das fortes críticas e das açóes de resistência desencadeadas pelos professores nas audiências públicas sobre a BNCC do Ensino Médio, promovidas pelo Conselho Nacional da Educação em diferentes regiōes do país, o governo insiste em prosseguir com a discussão e a aprovação do documento.

Sabemos que entre os pontos mais polêmicos da Reforma do Ensino Médio, náo esclarecidos pela versão proposta de adequação das Diretrizes Curriculares Nacionais do Ensino Médio (DCNEM), está a retirada das humanidades - Sociologia e Filosofia, Historia e Geografia —, enquanto disciplinas, dessa configuração incompreensível de "currículo por áreas de conhecimento". Como também não se pode ignorar o nexo entre a violência obscurantista desse posicionamento, aliás, uma tese partidária, e a crescente criminalização das diferenças, da pluralidade social, da diversidade das crenças e visōes de mundo, da civilidade, da nossa diversidade social e cultural que permeiam a fala de políticos e invadem o cenário dos debates pelas diferentes mídias. Diante desse quadro, não por acaso, amplifica-se o poder das forças totalitárias fundamentadas no raciocínio instrumentalizado, náo aceitando o fato de que são justamente tais diferenças aquilo que as pessoas têm em comum

O grande retrocesso da política educacional desse governo, o empobrecimento da escola pública, a negação da formação humanística, o desmonte da educação científica e tecnológica, em particular daquela arduamente construída nos Institutos Federais e nas escolas técnicas estaduais, conduzem a uma questão 
básica: qual é o projeto político pedagógico de formação da juventude do país, público por excelência da escola básica pública estatal?

O pragmatismo político e econômico das medidas educacionais impostas pelo governo Temer evidenciam acirramento do processo de aproximação entre escola e mercado e a implantaçáo do projeto de privatizaçáo do ensino público no Brasil. Não é mera coincidência, como já mencionamos, que os principais defensores dessa reforma e da BNCC do Ensino Médio sejam fundaçóes vinculadas e financiadas por grupos empresariais (Todos pela Educação, Fundação Lemann e Instituto Ayrton Senna, entre outros).

O cenário que se apresenta indica, assim, o crescente divórcio entre vontade popular e decisão política, quando as decisões dos governos, em nome de uma pretensa racionalidade econômica, propóem sacrificar as maiorias - trabalhadores e desempregados, aposentados e pensionistas, usuários de serviços públicos - para salvar ou ampliar os lucros de uma minoria. $\mathrm{O}$ atual governo golpista parece, inclusive, não fazer questão de ocultar o caráter de classe do Estado, esforço aparentemente considerado dispensável, aprofundando o que vem sendo chamado de "desdemocratização" (MIGUEL, 2018).

Mas, ao contrário do que pressupóem os arquitetos do golpe de 2016, um projeto político só pode resultar, como nos recorda Lefebvre (1973), de um "esforço coletivo, espontâneo e consciente, teórico e prático", em cuja elaboração cooperam as classes subalternas, "os grupos parciais e diferenciais, sobretudo os que o poder central rejeita para as periferias mentais, sociais e espaciais: as mulheres, os jovens, os 'desfavorecidos'”. E se as periferias são impotentes, se estão destinadas isoladamente às revoltas locais e pontuais, não deixam, por isso, de ter "a possibilidade de transbordar os centros", na medida em que estes são atingidos. Nessa direção, é importante mencionar que, contra as forças políticas quase hegemônicas no debate público e os grandes retrocessos sociais, ergue-se e cresce, em diferentes cantos do país, a mobilização de jovens das periferias nos grandes centros urbanos, de estudantes e professores da escola pública e das universidades.

É com essas preocupaçôes e análises do lugar da educação na "nova razão do mundo" (DARDOT; LAVAL, 2016) - no espaço exacerbado do neoliberalismo que pretende fabricar um "homem novo" (DUFOUR, 2005), que o Centro de Estudos Educação e Sociedade (CEDES) vai realizar, nos dias 10, 11 e 12 de dezembro próximo, o VI Seminário da Educaçáo Brasileira (SEB), com o objetivo de propiciar reflexão coletiva sobre a problemática "A educação no atual cenário político econômico mundial", para a qual convidamos todos os associados da entidade e leitores da revista.

Nesse contexto, o desafio que temos pela frente é encontrar estrutura e formas teórico-práticas capazes de sustentar um projeto educacional participativo e democrático, que promova o desenvolvimento integral dos estudantes, que legitime a liberdade da mente e dos corpos e um sistema justo e includente. Esse deasafio traduz as principais questóes do VI SEB. 
Atualmente, como vem afirmando o presente editorial, a educação brasileira atravessa um período conturbado, após grandes expectativas geradas a partir da Constituição de 1988, logo, em grande medida, frustradas pela Lei de Diretrizes e Bases da Educação Nacional (1996) e pelo Plano Nacional de Educação (2001). Essas esperanças foram, aos poucos, sendo desconstruídas com as mudanças ocorridas no cenário político-econômico que determinaram novas prioridades em prejuízo das políticas públicas, em especial no campo da educação.

A pressão dos agentes econômicos nacionais e internacionais fortaleceu uma nova onda de conservadorismo neoliberal. Ao mesmo tempo, foram desvelados impressionantes escândalos de corrupção em que, coordenadamente, setores estatais e privados juntaram forças para ampliar a privatização do Estado e a desconstrução do projeto público de nação e de uma sociedade mais igual e justa. Uma das estratégias desse projeto privatizante foi desacreditar a educação pública respaldada no preceito constitucional da concepção de educação como direito subjetivo e dever do Estado.

Considera-se que as questóes da educação estão sendo tratadas com base no gerencialismo e orientadas pela lógica mercantilista que a vê como mera mercadoria. Trata-se da implantaçáo de um modelo de desenvolvimento político, econômico e social humano pautado nos princípios do capital humano, por sua vez referenciado no modelo capitalista neoliberal. Nesses termos, as reformas educacionais que foram e vêm sendo implantadas mostram que o modelo educacional brasileiro está sendo ajustado aos interesses e às exigências da economia neoliberal global em prejuízo tanto da realidade nacional, com suas prerrogativas econômico-sociais, quanto dos ideais pedagógicos de formação humana.

No campo das políticas educacionais atualmente em curso, o que mais importa aos agentes do neoliberalismo é despolitizar e ajustar sistemicamente as pessoas conforme as supostas incontornáveis exigências da globalizaçáo, em flagrante desrespeito ao inequívoco dispositivo constitucional, segundo o qual cabe à educação promover o pleno desenvolvimento da pessoa, seu preparo para o exercício da cidadania e sua qualificação para o trabalho. Em sentido oposto, o interesse do sistema consiste na autotransformação do sujeito em agente produtivo cujas ambiçóes de autoestima não ultrapassem os limites da mais estrita subserviência aos interesses do capital. Nos termos das políticas públicas gerenciais, atualmente em curso, setores referentes aos direitos subjetivos, como educação, saúde e segurança, deixam de ser objeto de leis positivas para serem expostos à precarização da responsabilidade individual. Com isso, os setores sociais destituídos de recursos são relegados ao seu próprio destino e responsabilizados por seu fracasso. A educação pública, direito de todos e dever do Estado, é abandonada e, o quanto possível, privatizada em nome da falta de eficiência e de recursos que, no mais, náo faltam a outros setores de maior interesse econômico. 
Fazem parte dessa estratégia: a promulgação da Emenda Constitucional 95, de 16 de dezembro de 2016, que congela por 20 anos os investimentos em políticas públicas, inviabilizando a realizaçáo das metas do PNE; o não cumprimento da destinação de $10 \%$ do PIB para a educaçấo; a Lei no 13.429, de 31 de março de 2017, da terceirizaçáo irrestrita; a Lei no 13.467, de 13 de julho de 2017, da reforma trabalhista (trabalho intermitente); a Lei $n^{\circ}$ 13.415, de 16 de fevereiro de 2017, da reforma do ensino médio; e a resolução do Conselho Nacional da Educação CNE/CP no 2, de 22 de dezembro de 2017, que instituiu e orientou a implantaçáo da BNCC. O sujeito cidadáo deixa de ser a entidade de referência do modelo educacional posto, por inteiro, a serviço do sistema econômico. Os procedimentos e as exigências técnicas, impostos pelo sistema econômico neoliberal mundial, transformam, ultrapassando, em nome da eficiência e do desenvolvimento econômico, o limiar de qualquer visão política, social e ética do sujeito e da sociedade. Perde-se a noção de bem público acessível a todos por direito; dissolve-se o conceito de cidadania; transforma-se a educação/formaçáo em aprendizagem e treinamento; reduz-se a constituição própria do nacional e social, promovendo novas formaçôes de integração dos indivíduos e grupos que passam a ser modelados, em todas as esferas, privadas e sociais, sem garantias de mobilidade social e direito à igualdade. Essas constataçôes representam um desafio inarredável de pensar a educação neste novo cenário.

Ivany Rodrigues Pino ${ }^{1}$

${ }^{1}$ Editora. Universidade Estadual de Campinas - Campinas (SP), Brasil.

Luana Costa Almeida ${ }^{2}$

${ }^{2}$ Editora Assistente. Universidade do Vale do Sapucaí - Pouso Alegre (MG), Brasil.

Antonio Álvaro Soarez Zuin ${ }^{3}$

${ }^{3}$ Editor Associado. Universidade Federal de São Carlos - São Carlos (SP), Brasil.

Carmen Sylvia Vidigal Moraes ${ }^{4}$

${ }^{4}$ Editora Associada. Universidade de São Paulo - São Paulo (SP), Brasil.

Celso Joáo Ferretti 5

${ }^{5}$ Editor Associado. Centro de Estudos Educação e Sociedade, Universidade Estadual de Campinas - Campinas (SP), Brasil.

Pedro Goergen ${ }^{6}$

${ }^{6}$ Editor Associado. Universidade Estadual de Campinas - Campinas (SP), Brasil.

Salomáo Barros Ximenes ${ }^{7}$

${ }^{7}$ Editor Associado. Universidade Federal do ABC - Santo André (SP), Brasil.

Sandra Maria Zákia Lian Souza ${ }^{8}$

${ }^{8}$ Editora Associada. Universidade de São Paulo - São Paulo (SP), Brasil.

Theresa Adriáa ${ }^{9}$

${ }^{9}$ Editora Associada. Universidade Estadual de Campinas - Campinas (SP), Brasil. 


\section{Notas}

1 Sobre isso, ver: UCZAI, P. Caminhos a serem seguidos pelo Brasil na Educação. Carta Educação, 18 jun. 2018. Disponível em: <http://www.cartaeducacao.com.br/artigo/caminhos-a-serem-seguidos-pelo-brasil-na-educacao/?utm_campaign=newsletter_rd_-21062018\&utm medium=email\&utm source=RD+Station $>$. Acesso em: 20 jun. 2018.

\section{Referências}

BRAGA, R. A Rebeldia do Precariado. São Paulo: Boitempo, 2017.

DARDOT, P.; LAVAL, C. A nova razão do mundo: ensaio sobre a sociedade neoliberal. São Paulo: Boitempo, 2016.

DUFOUR, D.-R. A arte de reduzir as cabeças: sobre a nova servidão na sociedade ultraliberal. Rio de Janeiro: Companhia de Freud, 2005.

FOLHA DE S.PAULO. Sinecura patronal. Representantes do empresariado se perpetuam no comando de entidades sustentadas por recursos da sociedade. Folha de S.Paulo, 17 jul. 2018. Disponível em: shttps://www1.folha.uol.com.br/opiniao/2018/07/ sinecura-patronal.shtml?utm source=newsletter \&utm medium =email\&utm campaign=newsfolha?loggedpaywall?loggedpaywall $>$. Acesso em: 17 jul. 2018.

HARVEY, D. O novo imperialismo. São Paulo: Loyola, 2005.

LEFEBVRE, H. A re-produção das relações de produção. Porto: Publicações Escorpião, 1973.

MARTINS, J. de S. O poder oculto. Valor Econômico, 24 ago. 2018. Disponível em: <https://www.valor.com.br/imprimir/noticia/5765503/cultura/5765503/o-poderoculto $>$. Acesso em: 24 ago. 2018.

MIGUEL, L.F. Para além da democracia direta. Blog da Boitempo, 24 ago. 2018. Disponível em: $\quad \leq h t t p s: / / b l o g d a b o i t e m p o . c o m . b r / 2018 / 08 / 24 /$ para-alem-da-democracia-direta/ $>$. Acesso em: 26 ago. 2018. 